\title{
Dumpy-30 family members as determinants of male fertility and interaction partners of metal-responsive transcription factor I (MTF-I) in Drosophila
}

\author{
Alla Vardanyan ${ }^{1}$, Lilit Atanesyan1, Dieter Egli1 ${ }^{1}$, Sunil Jayaramaiah Raja², \\ Monica Steinmann-Zwicky ${ }^{3}$, Renate Renkawitz-Pohl², Oleg Georgiev ${ }^{1}$ and \\ Walter Schaffner*1
}

\begin{abstract}
Address: ${ }^{1}$ Institute of Molecular Biology, University of Zurich, Winterthurer St. 190, CH-8057 Zurich, Switzerland, 2 Philipps-University, Dept. Developmental Biology, Karl-von-Frisch-Str. 8, D-35043 Marburg, Germany and 3Zoological Institute, University of Zurich, Winterthurer St. 190, CH-8057 Zurich, Switzerland

Email: Alla Vardanyan - alla.vardanyan@molbio.unizh.ch; Lilit Atanesyan - lilit.atanesyan@molbio.uzh.ch;

Dieter Egli - degli@mcb.harvard.edu; Sunil Jayaramaiah Raja - raja@embl.de; Monica Steinmann-Zwicky - mstzw@zool.uzh.ch;

Renate Renkawitz-Pohl - renkawit@staff.uni-marburg.de; Oleg Georgiev - Ole@molbio.uzh.ch;

Walter Schaffner* - walter.schaffner@molbio.uzh.ch

* Corresponding author
\end{abstract}

\section{Published: 27 June 2008}

BMC Developmental Biology 2008, 8:68 doi:10.1/86/147I-2/3X-8-68

This article is available from: http://www.biomedcentral.com/I47I-2/3X/8/68

(c) 2008 Vardanyan et al; licensee BioMed Central Ltd.

This is an Open Access article distributed under the terms of the Creative Commons Attribution License (http://creativecommons.org/licenses/by/2.0), which permits unrestricted use, distribution, and reproduction in any medium, provided the original work is properly cited.
Received: 10 April 2008

Accepted: 27 June 2008

\begin{abstract}
Background: Metal-responsive transcription factor I (MTF-I), which binds to metal response elements (MREs), plays a central role in transition metal detoxification and homeostasis. A Drosophila interactome analysis revealed two candidate dMTF-I interactors, both of which are related to the small regulatory protein Dumpy-30 (Dpy-30) of the worm C. elegans. Dpy-30 is the founding member of a protein family involved in chromatin modifications, notably histone methylation. Mutants affect mating type in yeast and male mating in $C$. elegans.

Results: Constitutive expression of the stronger interactor, Dpy-30LI (CG6444), in transgenic flies inhibits MTFI activity and results in elevated sensitivity to $\mathrm{Cd}(\mathrm{II})$ and $\mathrm{Zn}(\mathrm{II})$, an effect that could be rescued by cooverexpression of dMTF-I. Electrophoretic mobility shift assays (EMSA) suggest that Dpy-30LI interferes with the binding of MTF-I to its cognate MRE binding site. Dpy-30LI is expressed in the larval brain, gonads, imaginal discs, salivary glands and in the brain, testes, ovaries and salivary glands of adult flies. Expression of the second interactor, Dpy-30L2 (CGII59I), is restricted to larval male gonads, and to the testes of adult males. Consistent with these findings, dpy-30-like transcripts are also prominently expressed in mouse testes. Targeted gene disruption by homologous recombination revealed that $d p y-30 \mathrm{LI}$ knockout flies are viable and show no overt disruption of metal homeostasis. In contrast, the knockout of the male-specific $d p y-30 L 2$ gene results in male sterility, as does the double knockout of $d p y-30 L I$ and dpy-30L2. A closer inspection showed that Dpy-30L2 is expressed in elongated spermatids but not in early or mature sperm. Mutant sperm had impaired motility and failed to accumulate in sperm storage organs of females.
\end{abstract}

Conclusion: Our studies help to elucidate the physiological roles of the Dumpy-30 proteins, which are conserved from yeast to humans and typically act in concert with other nuclear proteins to modify chromatin structure and gene expression. The results from these studies reveal an inhibitory effect of Dpy-30LI on MTF-I and an essential role for DPy-30L2 in male fertility. 


\section{Background}

Metal-responsive transcription factor 1 (MTF-1) can cooperate, in a positive or negative manner, with other transcription factors binding to their own DNA sites nearby (USF1, [1]; NFI, [2,3]; Sp1, [4]; NF-kB [5]), but no MTF-1specific coactivators or corepressors were described so far. A general interaction analysis of Drosophila proteins by means of the yeast two-hybrid system [6] revealed two closely related proteins as potential interaction partners of MTF-1 (see below). These interaction proteins were encoded by genes designated CG6444 and CG11591 [7]. Both belong to a protein family that is conserved from yeast to humans and whose founding member was described in the nematode C. elegans as Dumpy-30 (Dpy30 ), a protein involved in dosage compensation of sex chromosomes [8]. Dpy-30 is required for sex-specific association of Dpy-27, a chromosome condensation protein homolog, with the hermaphrodite's $\mathrm{X}$ chromosomes. Besides causing XX-specific lethality, the $d p y$ - 30 mutation in XO animals causes developmental delay, small body size, inability to mate and abnormal tail morphology [9]. These phenotypes suggest an involvement of Dpy-30 also in processes other than dosage compensation. The yeast homolog of C. elegans Dpy-30, Sdc1, was identified as an important component of the eight-member complex (SET1C protein complex), which functions as a histone 3 lysine 4 (H3-K4) methyltransferase [10]. The loss of individual SET1 protein complex subunits differentially affects SET1 stability, complex integrity and the distribution of H3K4 methylation along active genes. Such mutations cause defects in maintenance of telomere length [11] and in DNA repair $[12,13]$. Dpy-30 and its close relatives contain a short motif related to the dimerization motif in the regulatory subunit of Protein Kinase A. This motif consists of two $\alpha$-helices that form a special type of four-helix bundle during dimerization [14]. Until recently no data were available on one of the Drosophila homologs, CG6444, while the other, CG11591, was shown to be expressed in testes by genome-wide microarray analysis of transcription [15].

As mentioned, the interaction partner of Dpy-30-like proteins in the Drosophila interaction study was identified as metal-responsive transcription factor 1 (MTF-1). MTF-1 is a key regulator of heavy metal homeostasis and detoxification in higher eukaryotes [16-19]. In mammals, MTF-1 controls a number of genes for metal homeostasis and is also essential for embryonic liver development [20-23].

MTF-1 binds via its zinc fingers to metal-responsive elements (MREs) in the promoter/enhancer region of target genes $[16,24]$ and activates their transcription. Metallothioneins are the best characterized target genes of MTF1 ; they encode small, cysteine-rich proteins with an ability to scavenge excess heavy metal ions [25-27]. Drosophilae mutant for dMTF-1, the homolog of mammalian MTF-1, are viable but more sensitive to elevated concentrations of heavy metals, as well as to copper scarcity [28]. Upon copper starvation, dMTF-1 activates transcription of the gene encoding Ctr1B, a high affinity copper importer [29]. Recently several additional target genes of MTF-1 in mammals and in Drosophila were identified and characterized in our laboratory by microarray and specific transcript analysis [30,31] but little is known to date about proteins interacting with and/or regulating Drosophila MTF-1 function.

Here we show that transgenes of both Drosophila Dpy-30 orthologs, CG6444 and CG11591, hereafter termed Dpy30-like 1 (Dpy-30L1) and Dpy-30-like 2 (Dpy-30L2), respectively, inhibit MTF-1-dependent reporter gene expression in cell culture. Constitutive expression of a Dpy-30L1 transgene in flies results in elevated sensitivity to Cd(II) and Zn(II), while Dpy-30L2 overexpression has no such effect. Consistent with metal resistance, only the Dpy-30L1 transgene inhibited dMTF-1 activity in flies. Gene knockout by homologous recombination revealed that $d p y$-30L1 null mutant flies are viable and fertile and maintain a seemingly normal metal homeostasis, while knockout of the male-specific $d p y$-30L2 results in male sterility. Sperm motility in $d p y-30 L 2$ mutants is impaired and drastically decreases with age. After mating mutant sperm is transferred to the uterus but does not accumulate in the seminal receptacle and spermathecae, making successful fertilization impossible. These findings reveal a major role of Dpy-30 proteins in male fertility and sperm motility.

\section{Results \\ Inhibition of MTF-I-dependent reporter expression in Drosophila Schneider S2 cells}

The Drosophila interactome study of Giot et al. [6] had revealed three proteins that display very good (Dpy30L1), good (Dpy-30L2), and weak (CG11061) interaction with dMTF-1. In order to characterize the role of these proteins in Drosophila, especially in the context of metal homeostasis, the open reading frames (Figure 1) of all three were cloned into a Drosophila expression vector and analyzed by transfection and co-transfection studies in insect cells. The third protein reported to interact with dMTF-1 only weakly, CG11061, was listed as a protein putatively involved in Golgi organization and biogenesis, mitosis and protein targeting. In our hands it did not affect MTF-1 function (data not shown), thus rendering doubtful a physiological relevance of the predicted interaction.

In Drosophila Schneider S2 cells [32], transfection of $d p y$ $30 L 1$ or $d p y$-30L2 inhibited the expression of MTF-1dependent reporter genes driven either by the promoter of the Drosophila metallothionein A (MtnA) (not shown) or 


Dpy-30" core.
DpY-30L1
Dpy-30L2
Human
Mouse
C.elegans
Yeast

Dpy-30" core DPY-30L1
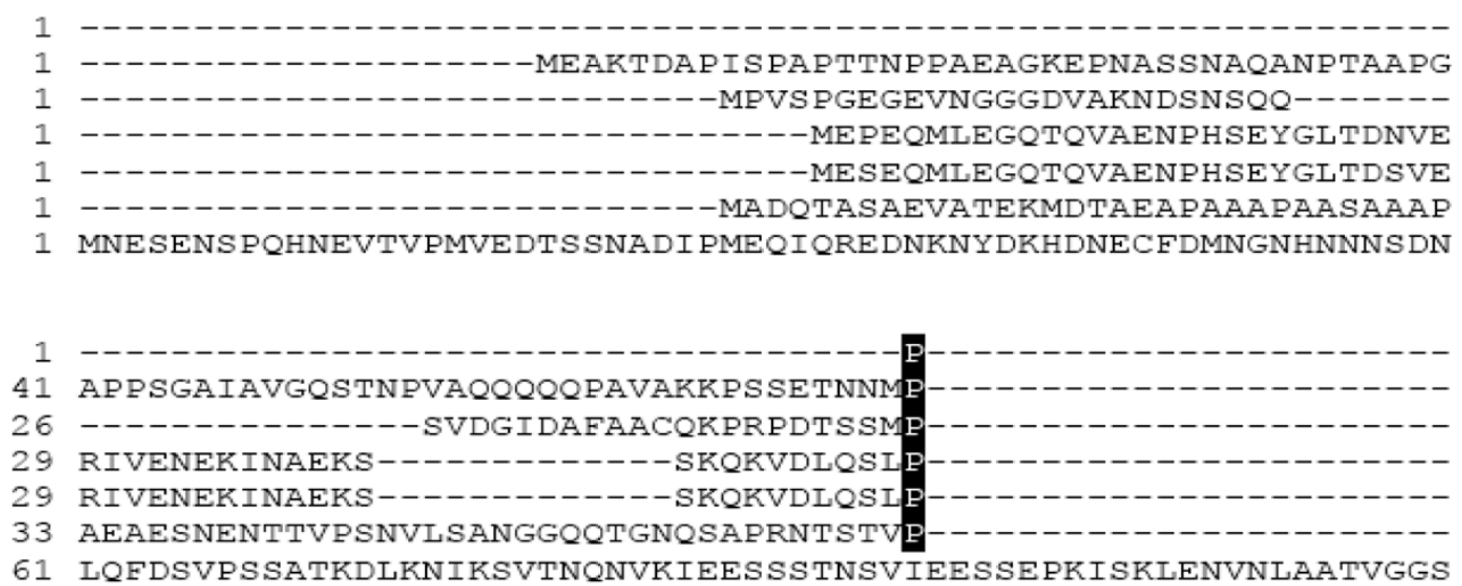

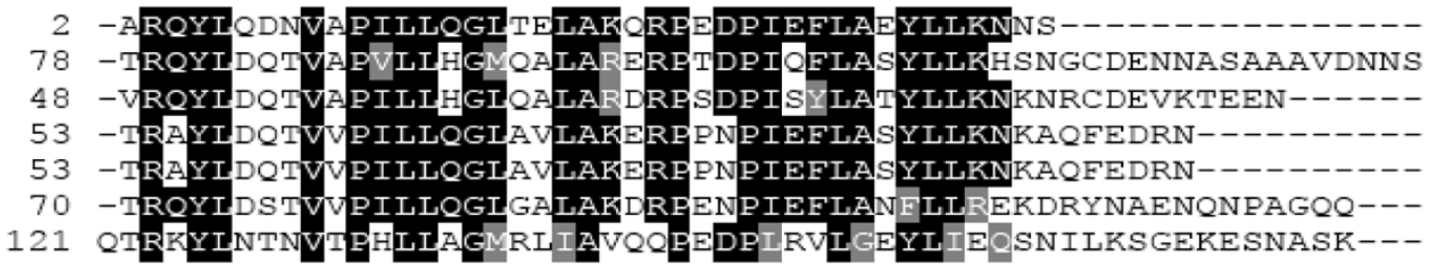

Figure I

Alignment of Drosophila Dpy-30LI and Dpy-30L2 with their orthologs from different species. The core domain of these short proteins is highly conserved among different species. Grey shaded: similar, black shaded: identical aa. Dpy-30 " core" indicates the consensus core sequence.

by a synthetic promoter consisting of four tandem metal response elements (MREs), the binding sites of MTF-1 (Figure 2A). The effect on the synthetic MRE promoter was more pronounced, suggesting that Dpy-30L1 and Dpy30L2 indeed interact with dMTF-1 and thereby interfere with its activity, as MTF-1 is the only factor known to bind MREs. This inhibitory effect could also be shown in the whole organism expressing an YFP reporter gene driven by the metallothionein (MtnA) promoter (Figure 2B). Here, the response (YFP expression) to copper, and especially to cadmium, was strongly reduced, whereas under copper starvation conditions no difference was observed.

Due to the high degree of conservation among all the members of this protein family, we screened the mouse and human genome for the orthologs (Figure 1) and subcloned the Dpy-30-like members both from mouse and human. These mammalian Dpy-30-like proteins were as effective as the Drosophila proteins in repressing dMTF-1 activity in Drosophila Schneider cells (Figure 3B and not shown). However, it appears that the antagonistic interaction between MTF-1 and Dpy-30 family members is specific to Drosophila MTF-1: mammalian MTF-1 was not affected by Dpy-30-type proteins, irrespective of whether the test was done in Drosophila cells (Figure 3) or mammalian cells (not shown).

To gain further insights to the inhibitory effect of Dpy30L1 on dMTF-1, we did an electrophoretic mobility shift assay (EMSA) of transfected VSV-tagged MTF-1, without or with co-transfected $d p y$-30L1. The reduced band intensity of the shifted MRE oligo suggests that Dpy-30L1 interferes with binding of MTF-1 to its cognate MRE DNA (Figure 4).

\section{Flies overexpressing Dpy-30L I are sensitive to heavy metal load}

We generated transgenic flies with ubiquitous, constitutive expression of $d p y$-30L1 or $d p y$-30L2, taking advantage of the UAS-Gal4 system whereby Gal4 was driven by the Drosophila actin promoter. Flies overexpressing Dpy-30L1 were raised during their entire development on normal food, or food supplemented with different heavy metals. They did not show a phenotype when kept on standard food but were much more sensitive to heavy metal load, especially to cadmium and zinc, while sensitivity to copper was only marginally affected (Figure 5). The sensitivity to cadmium and zinc could be rescued by co-overexpression of an MTF-1 transgene (Figure 5). This shows that the 


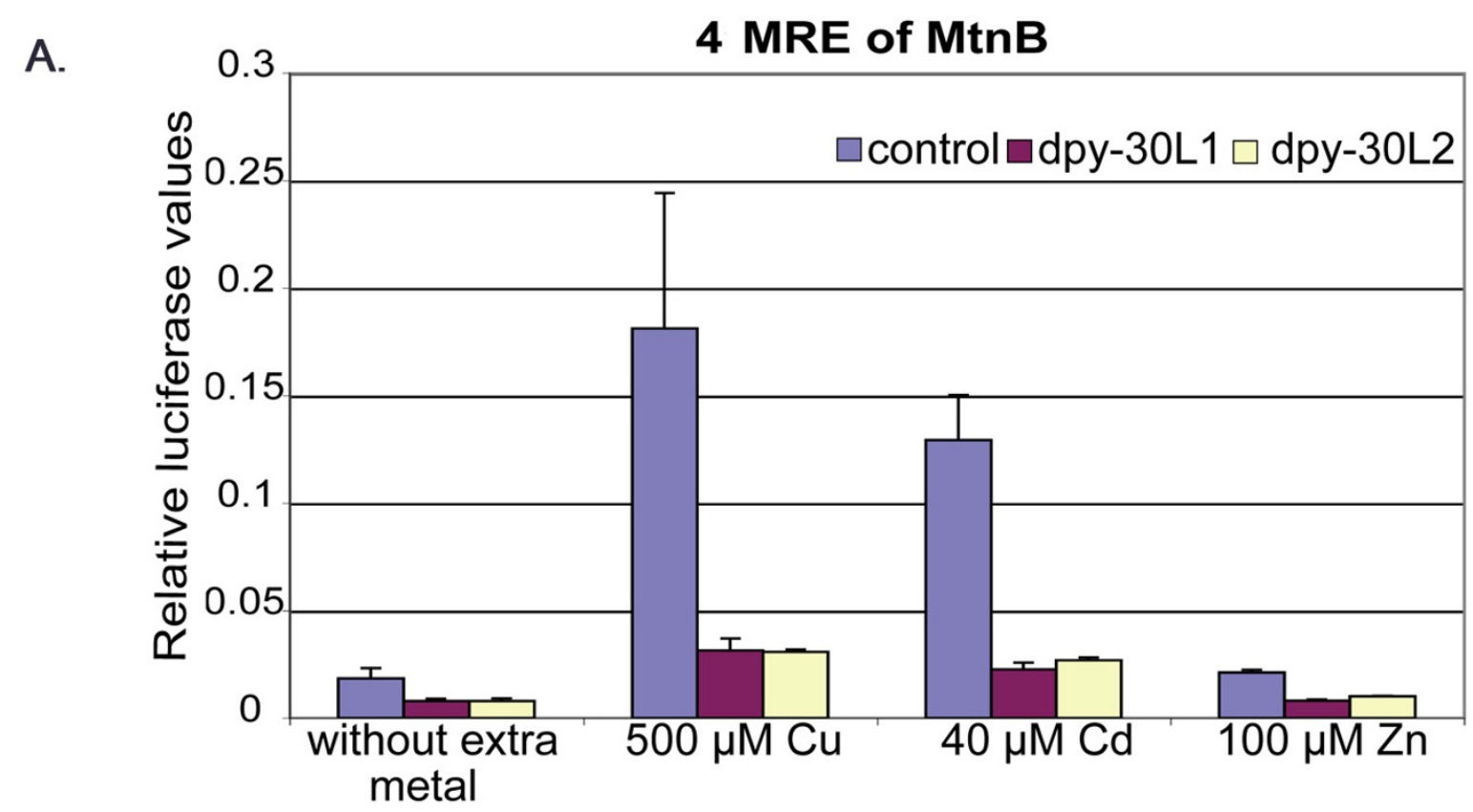

B.

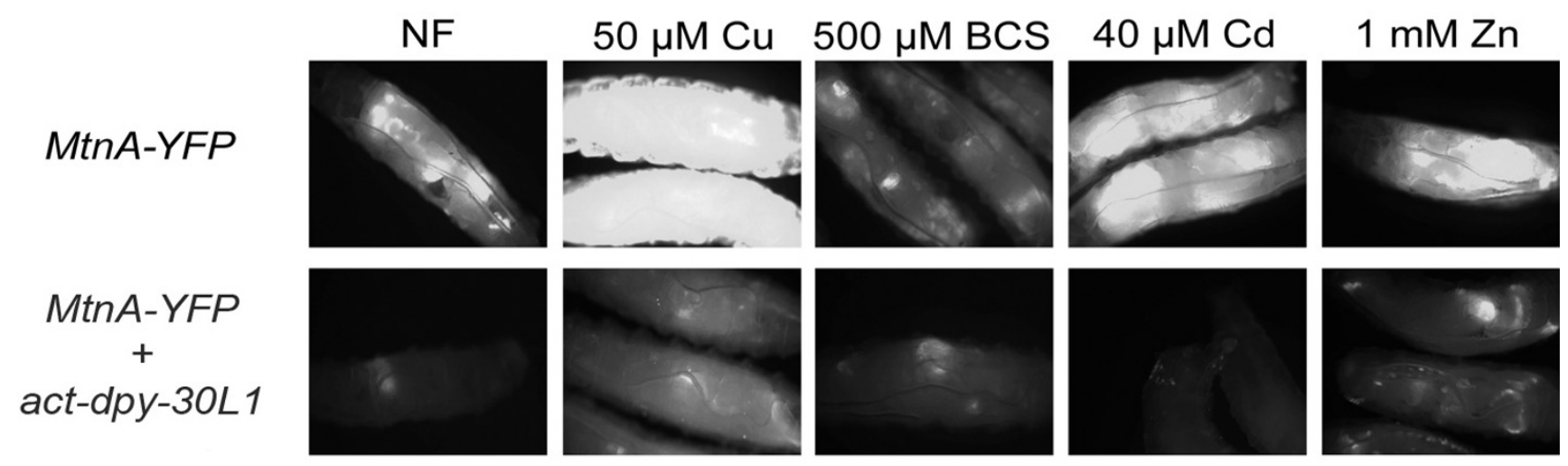

Figure 2

Effect of Dpy-30LI overexpression on MTF-I dependent reporters in cell culture and in vivo. A) In transiently transfected Drosophila Schneider S2 cells [32], the ratio of firefly (reporter) to renilla (reference) luciferase activity is shown. Reporter: 4xMRE from the metallothionein B (MtnB) promoter [18] fused to firefly luciferase; reference: tubulin promoter fused to renilla luciferase [53]. Dpy-30LI and Dpy-30L2 expression constructs were under the control of the actin promoter. 72 hours after transfection, cells were treated with the indicated concentrations of heavy metals for 24 hours. B) Expression level of green fluorescent protein in transgenic larvae that carry an MtnA-YFP reporter construct. Transgenic flies were allowed to lay eggs on normal food or food supplemented with different heavy metals.

metal sensitivity of organisms expressing transgenic Dpy30L1 was not merely reflecting a generally lower resistance to stress but rather a disturbed metal-specific stress response. This point was corroborated by raising flies in excess iron, a metal that is handled by a pathway different from the MTF-1/metallothionein system. Neither an increased sensitivity nor a rescue effect could be observed upon overexpression of Dpy-30L1 and/or dMTF-1 (data not shown). Although both Dpy-30L1 and Dpy-30L2 overexpression inhibited MTF-1 function in cell culture, only Dpy-30L1 was effective in a transgenic fly. This leads to the conclusion that there are functional differences 
A.

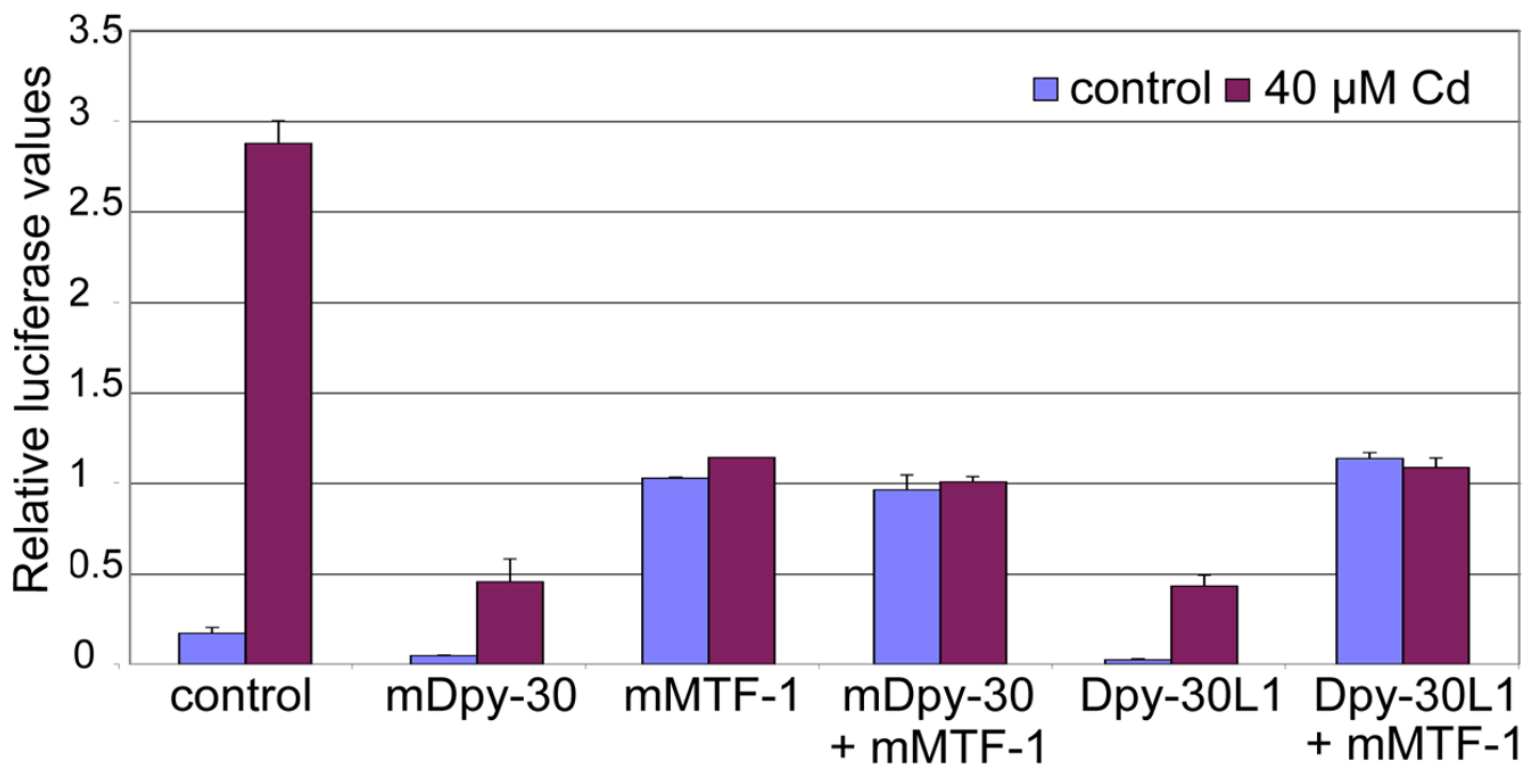

B.

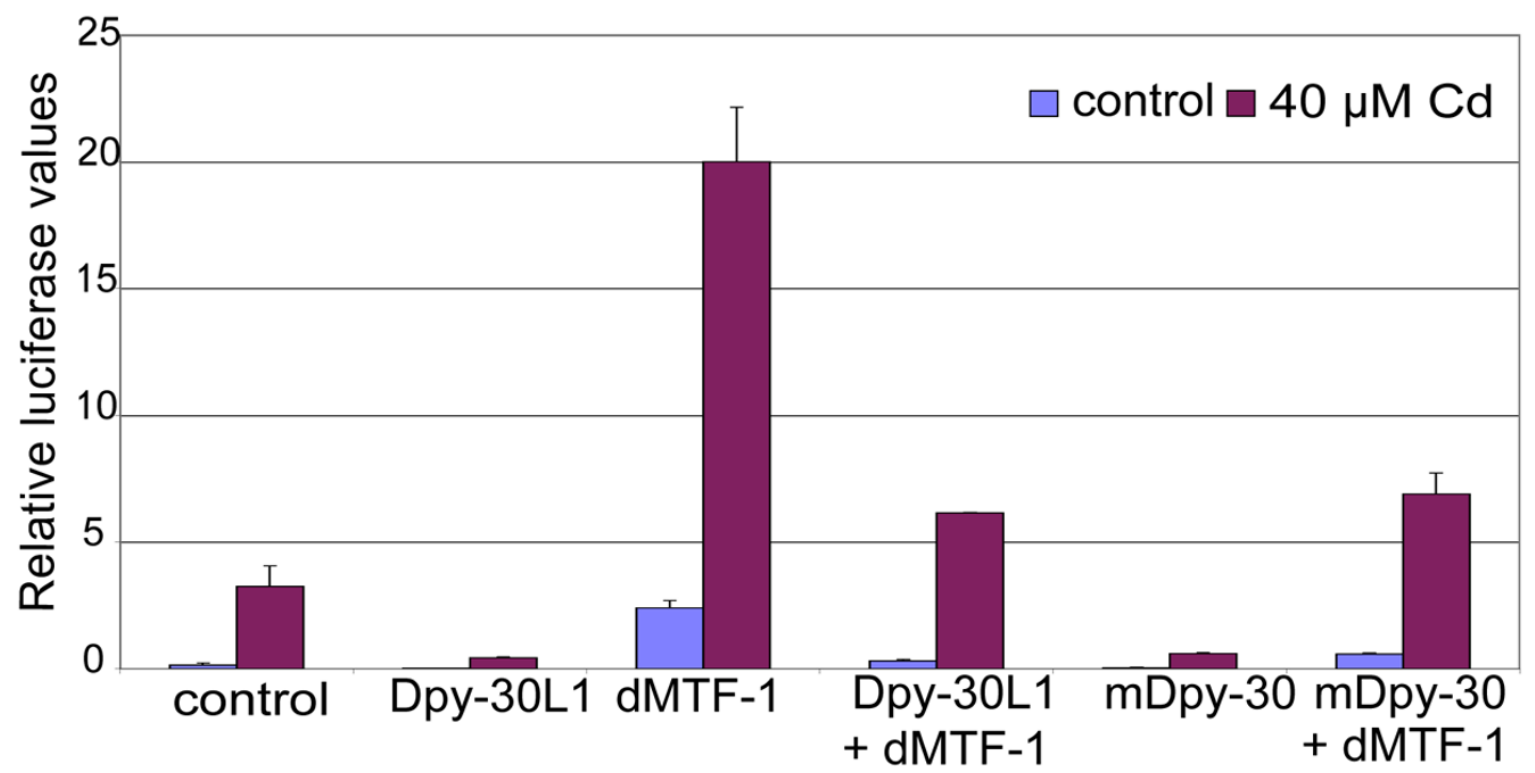

Figure 3

Inhibitory effect of Dpy-30LI, Dpy-30L2 and their mammalian orthologs is restricted to Drosophila MTF-I. The ratio of firefly to renilla luciferase activity in transiently transfected Drosophila Schneider S2 cells is shown. Reporter, MtnA promoter fused to firefly luciferase; reference, tubulin promoter fused to renilla luciferase. Dpy-30LI and the mouse ortholog were under the control of the actin promoter. 72 hours after transfection, the medium in half of the plates was supplemented with $40 \mu \mathrm{M}$ cadmium chloride for 24 hours, while the others served as controls. A) Mouse MTF-I was co-transfected in the indicated samples; B) Drosophila MTF-I was co-transfected in the indicated samples. 


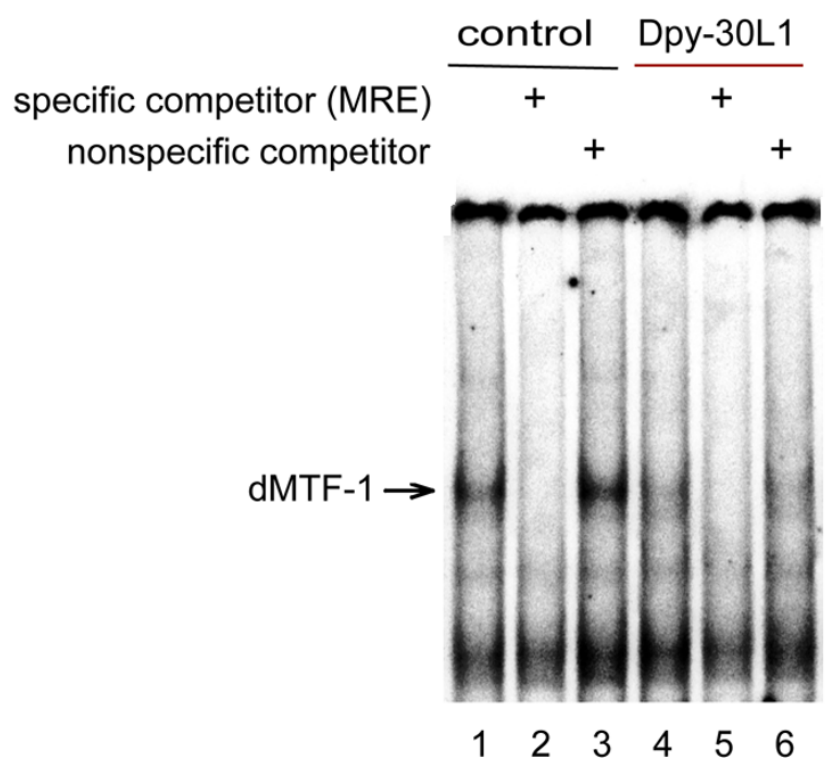

Figure 4

Reduced DNA binding of dMTF-I upon co-expression of Dpy-30LI. DNA binding by dMTF-I was determined by EMSA. Drosophila S2 cells were transfected with VSV tagged dMTF-I expression plasmids, and $20 \mu \mathrm{g}$ of nuclear protein extract was used for each bandshift reaction. Lanes I and 4, bandshift with [32P]-labeled MRE consensus oligonucleotide (MRE-s). Lanes 2 and 5, same conditions but also including a 200-fold excess of unlabeled MRE-s competitor oligonucleotide (specific competitor). Lanes 3 and 6, same conditions but with a 200 -fold excess of unlabeled Sp I oligonucleotide (nonspecific competitor). Cells had been treated for 6 hours with medium containing $100 \mu \mathrm{M}$ zinc sulfate.

between the two related proteins that become evident only in whole-organism studies.

\section{Expression pattern of Dpy-30LI and Dpy-30L2}

To determine the expression pattern of both genes in larvae and adult flies, transgenes were constructed where a fluorescent reporter (YFP) was under the control of approximately $7 \mathrm{~kb}$ of genomic region from Dpy-30L1 or Dpy-30L2. The expression pattern of the two genes was quite distinct: The $d p y$-30L1 regulatory region induced expression in multiple larval tissues, notably brain, gonads, imaginal discs and salivary glands. In adult flies, expression was seen in the brain, testes, ovaries and salivary glands. In contrast, the expression of Dpy-30L2-YFP was confined exclusively to male gonads in larvae, and to the testes in adult flies. Further dissection of the expression pattern of Dpy-30L2-YFP during spermatogenesis revealed that Dpy-30L2-YFP is expressed in elongated spermatids at the "canoe-like" stage but not during the early stages of spermatogenesis or in mature sperm (not shown), which is also consistent with the online Drosophila testis gene expression database [33]. The expres- sion pattern of these transgenic constructs was very similar to the ones derived from a genome-wide transcription map recently published online in Flyatlas [34,35].

Targeted gene disruption shows that Dpy-30L2 is essential for male fertility

In order to determine the in vivo role of the two Dpy-30like proteins, we disrupted both of the corresponding genes by means of homologous recombination [36]. Somewhat unexpectedly, $d p y-30 L 1$ knockout flies turned out to be viable and fertile under laboratory conditions and did not show any obvious alterations in metal resistance/sensitivity phenotypes (data not shown). In the mutated locus, the yellow fluorescent protein (YFP) and SV40 polyadenylation/termination sequence was followed, out-of-frame, by a truncated Dpy-30L1 coding sequence (for details, see Materials \& Methods). Though unlikely, we cannot rule out the possibility that the residual Dpy-30L1 sequence was expressed by re-initiation of transcription and translation from an internal site in the coding region, thus producing a hypomorph, rather than a null mutation. In contrast, disruption of the male-specific $d p y$-30L2 gene resulted in complete male sterility. Combination of the two mutations did not reveal any additional phenotypic features, i.e., male flies were again sterile but otherwise normal under laboratory conditions.

We attempted to identify more precisely the defects in the reproductive system of $d p y$-30L2 knockout males. A dissection of $d p y-30 L 2^{6-1}$ males revealed apparently normal testes that contained sperm. In the nematode C. elegans, Dpy-30 is known to be involved in dosage compensation, a process that equalizes the expression of X-chromosomes in XX and XO animals [8], and in yeast it methylates histones $[38,39]$. Dpy-30L2 is specifically expressed in the spermatid stage where transcription is repressed in germ cells and histones are removed from DNA to be replaced by protamines. Thus we wondered whether in Drosophila, loss of Dpy-30L2 distorts chromatin structure at this critical stage. However, loss of histone $\mathrm{H} 2 \mathrm{~A}$ variant $\mathrm{D}$ (H2AvD) expression, a hallmark of the transition to the protamine-loaded sperm, was not affected (Figure 6), and also the protamine B-eGFP distribution pattern was not disturbed. Furthermore, the marker Mst77F-eGFP was inconspicuous in that it was associated with DNA at the appropriate stage of spermatogenesis (Figure 6). Mst77F is a distant relative of the linker histone $\mathrm{H} 1 / \mathrm{H} 5$ family and has been proposed to support the transition to compact Drosophila sperm chromatin $[39,40]$. Unlike its mammalian homolog (mHILS1), Drosophila Mst77F persists in mature sperm nuclei [40].

However, we found one clear difference between mutant and wild type flies: dissection of the reproductive tract of females that had mated with dpy-30L2 mutant males 


$$
\begin{aligned}
& \text { Crosses: } y w ;+; \frac{\text { act-Gal4, tub-MTF-1 }}{T M 3, \operatorname{Ser}, P\{y+\}} \quad x \quad y w ;+; \frac{U A S-d p y-30 L 1}{T M 2, P\{y+\}} \square \begin{array}{c}
\text { Dpy-30L1 } \\
\text { and dMTF-1 } \\
\text { overexpr. }
\end{array} \\
& y w ;+; \frac{\text { act-Gal4 }}{\text { TM3, Ser, } P\{y+\}} \quad x \quad y w ;+; \frac{U A S-d p y-30 L 1}{T M 2, P\{y+\}} \square \text { Dpy-30L1 }
\end{aligned}
$$

\section{Ratio of overexpressors to control flies expected to be 0.5}

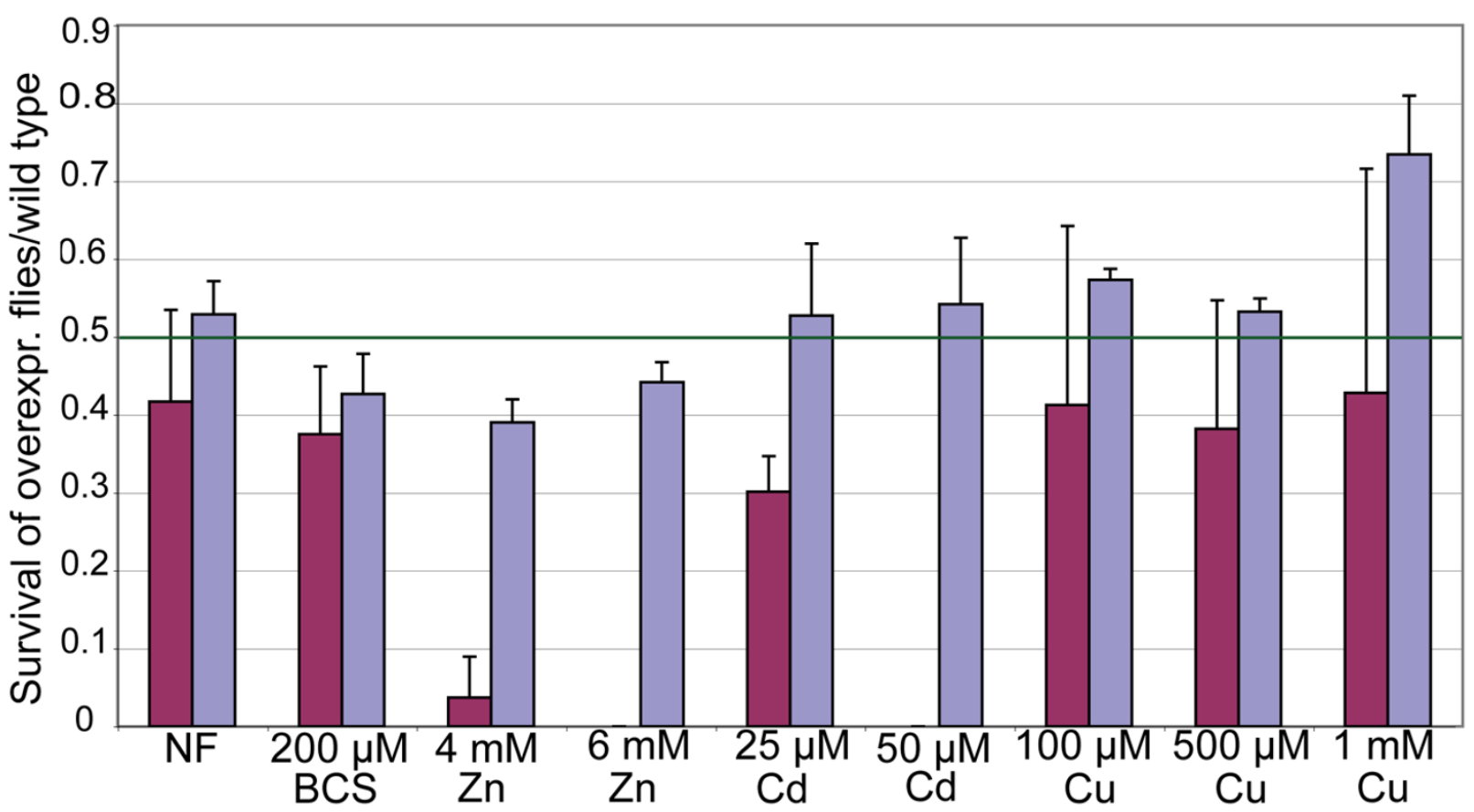

Figure 5

Sensitivity of Drosophila to heavy metal load. Crosses of flies with the indicated genotypes were done on normal food (NF) or on food supplemented with the indicated metals. Flies were allowed to lay approximately the same amount of eggs, then in each tube the ratio of eclosed Dpy-30LI overexpressors to controls was determined. In normal food, the cross was expected to yield $\mathrm{I} / 3$ overexpressors and $2 / 3$ controls i.e., a ratio of 0.5 , which is indicated by a green line. act - actin, tub tubulin.

revealed that sperm were confined to the uterus, which means that they had failed to be transmitted to the seminal receptacle and the spermathecae (Figure 7). Since from these latter sites sperm are used to fertilize eggs, this mislocalization could, in part or completely, explain the sterility of mutant males. A possible reason for mislocalization of dpy-30L2 mutant sperm in females could be impaired or uncoordinated motility of sperm. Dissection of the reproductive tract of females that had been mated either with Oregon $\mathrm{R}$ or with $d p y-30 L 2^{6-1}$ males showed that $d p y$-30L2 knockout sperm indeed lose their motility after transfer to the female reproductive tract (Table 1).
More detailed analysis of sperm amount and motility in males revealed an age-dependent decrease in both amount and motility of $d p y-30 L 2^{6-1}$ sperm, with complete loss of motility in 20-day-old males in contrast to heterozygous males. Taken together, these results reveal that Dpy-30L2 is important for sperm production and motility.

\section{Discussion}

In transfected cells, both of the Dpy-30 orthologs of Drosophila, termed Dpy-30L1 and Dpy-30L2 (Dumpy-30like1 and -like2), inhibit the activity of MTF-1 (metal- 


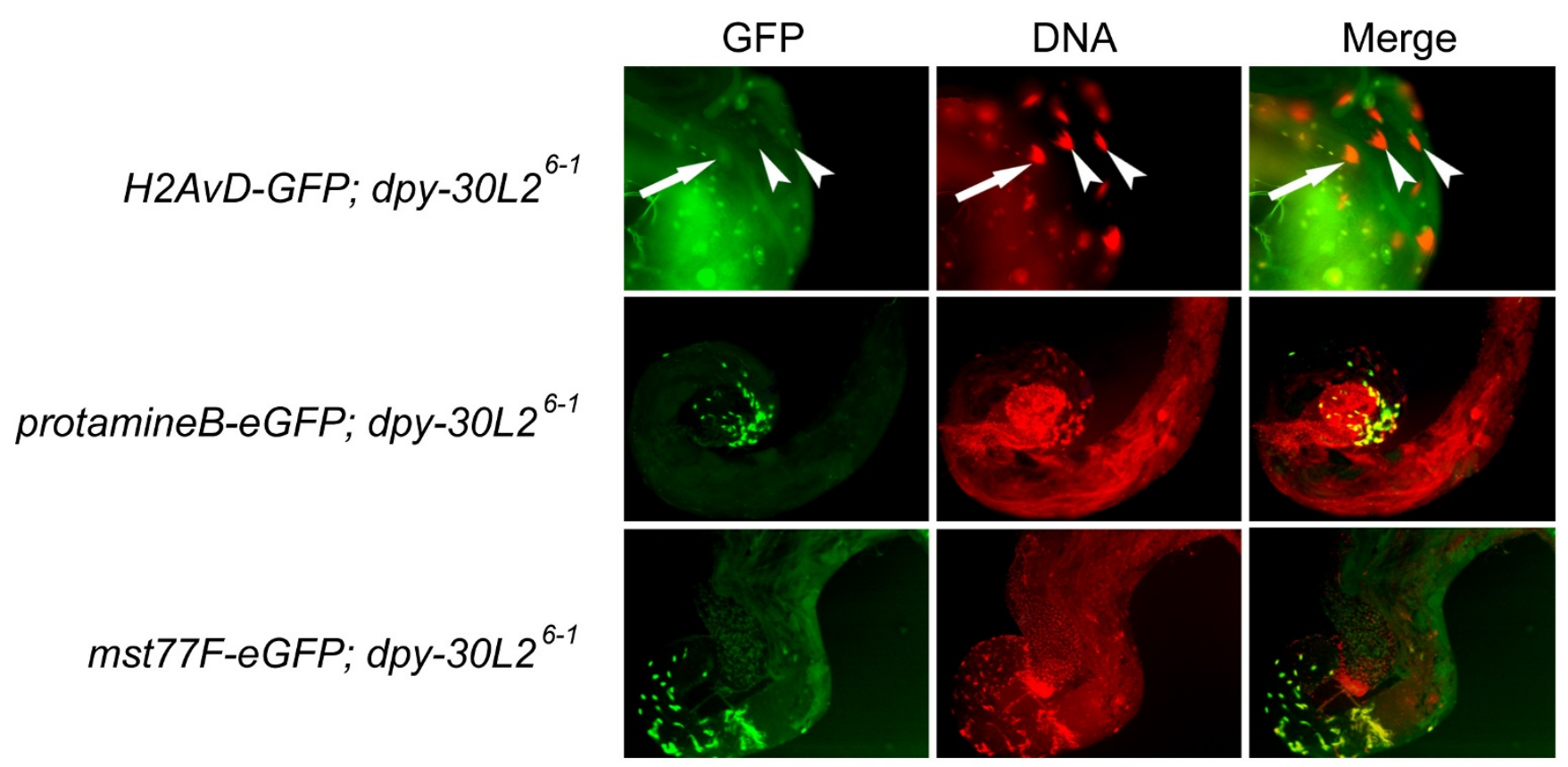

\section{Figure 6}

Transition of histones to protamines in dpy-30L2 knockout males. Degradation of histones was checked in $d p y-30 L 2$ knockout (dpy-30L26-1) males carrying a transgene with a fusion of GFP to the coding sequence of the histone $H 2 A D$ variant $(\mathrm{H} 2 \mathrm{AvD})$. Arrow, H2AvD-GFP in degradation; arrowheads, H2AvD-GFP degraded. Incorporation of protamine B and Mst77F was analyzed in dpy-30L2 knockout males that carry either a transgene of protamine B fused to eGFP or of Mst77F fused of eGFP. During the "canoe" and "post-canoe" stages of spermatid development, ProtamineB-eGFP and Mst77F-eGFP incorporation in the spermatid nucleus appeared to be normal in dpy-30L2 knockout males. Any (diffuse) YFP signal from the $d p y-30 L 2$ promoter was not filtered out.

responsive transcription factor 1), while in transgenic flies, such an effect was only seen with the stronger interactor Dpy-30L1. Consistent with such an inhibition, transgenic flies were sensitive to cadmium or zinc load, while copper sensitivity was only marginally affected. The increased metal sensitivity could be rescued by co-overexpression of dMTF-1. An EMSA assay revealed a weakened binding of MTF-1 to MRE DNA in the presence of Dpy30L1. Taken together, these results suggest that for detoxification of $\mathrm{Cd}(\mathrm{II})$ or $\mathrm{Zn}(\mathrm{II})$ a higher level of MTF-1 is required than for $\mathrm{Cu}(\mathrm{II})$ detoxification. Studies with partial inactivation mutants of dMTF-1 are in agreement with such a notion (A.V., H. Yepiskoposyan and W.S., unpublished). Unexpectedly, only MTF-1 of insect origin responded to Dpy-30 type proteins: while the human and mouse Dpy-30 members also inhibited Drosophila MTF-1 across species boundaries, activity of human MTF-1 was unchanged in the presence of either Drosophila or mammalian Dpy-30 members. This indicates some degree of functional divergence between Drosophila and mammalian MTF-1 during evolution, in spite of a conserved role in heavy metal homeostasis and detoxification. We consider the Dpy-30-dMTF-1 interactions observed in the interactome study [6] relevant because (i) the two major interactors Dpy-30L1 and L2 are members of the same protein family; (ii) a (negative) functional interaction with dMTF-1 was seen with both of them, and with their mammalian Dpy-30 homolog, in transfected cells; (iii) Dpy-30L1, the stronger interactor, also produced an effect in vivo, and (iv) it inhibited the binding of dMTF-1 to its cognate DNA sequence.

As a complement to transgenic expression of Dpy-30L1 and Dpy-30L2, we also tested a loss of function of the two proteins. Disruption of short genes in Drosophila has been a great challenge since small targets are rarely hit by random mutagenesis. To circumvent this problem, we eliminated Dpy-30L1 and L2 function separately by homologous recombination $[36,41]$. Somewhat unexpectedly, knockout of neither Dpy-30L1 nor Dpy-30L2 affected metal handling under the conditions tested, but Dpy-30L2 which is specifically expressed in male gonads, turned out to be essential for male fertility.

Sdc1, the yeast homolog of Dpy-30, is a component of SET1C, also called COMPASS (complex proteins associated 

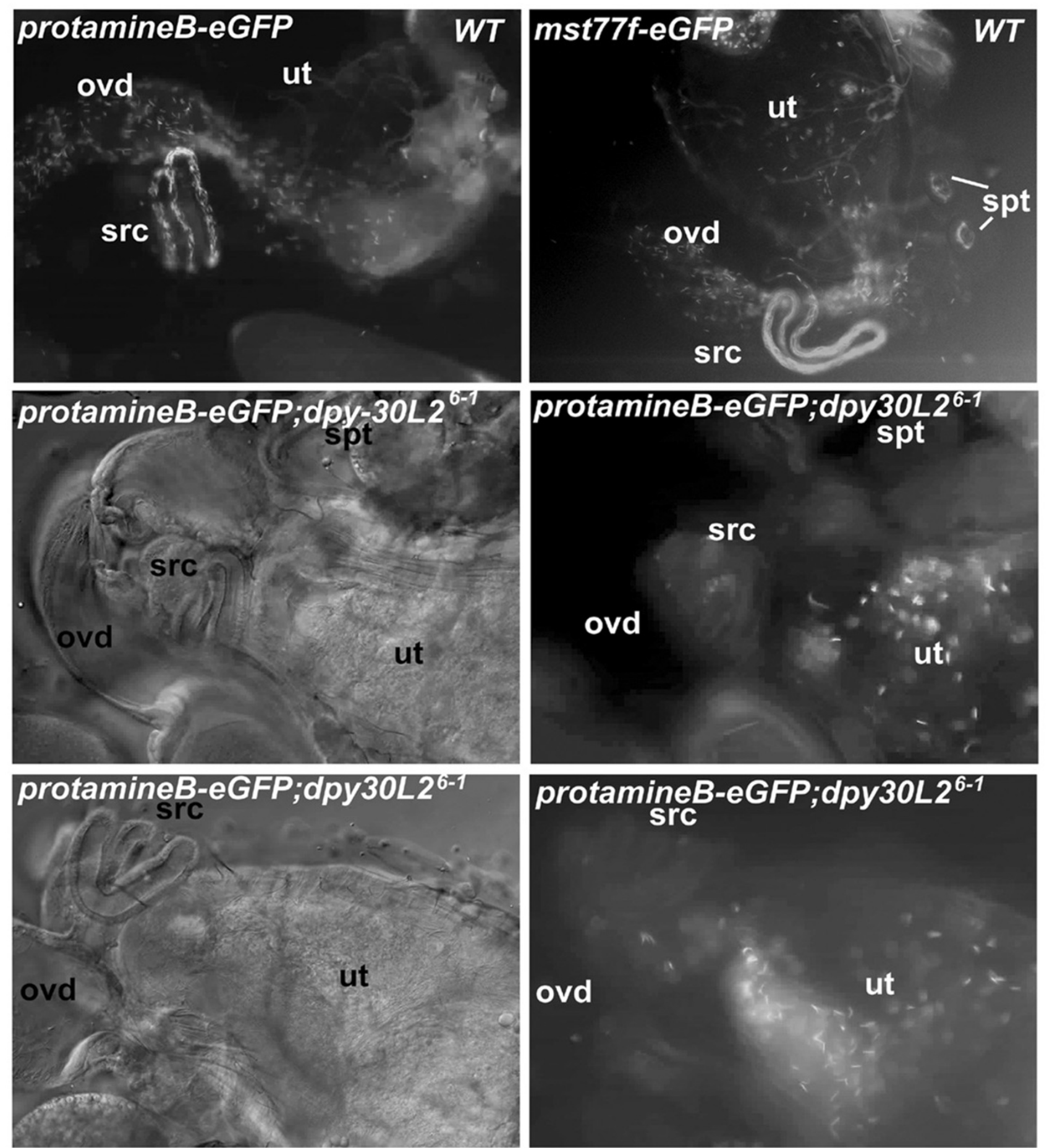

\section{Figure 7}

Dpy-30L2 knockout sperm in the wild type female reproductive system. Sperm of wild type males were marked by Mst77F or protamineB fused to eGFP to follow its fate in the female reproductive system. Wild type females were allowed to mate with wild type or mutant males, the females were then dissected and checked for a GFP signal in their reproductive system. 30 minutes after mating, $20 \%$ of wild type sperm had accumulated in female storage organs. However, mutant sperm remained in the uterus and failed to be transferred to seminal receptacle and spermathecae, the female sperm storage organs. Ov - ovaries; spt - spermatheca; src - seminal receptacle; ut - uterus; ovd - oviduct. 
Table I: Sperm presence and motility in female reproductive tract

\begin{tabular}{|c|c|c|c|c|c|c|c|}
\hline \multirow[t]{2}{*}{ Male genotype } & \multirow[t]{2}{*}{$\begin{array}{l}\text { Female } \\
\text { genotype }\end{array}$} & \multirow[t]{2}{*}{ Days after cross } & \multirow[t]{2}{*}{$\begin{array}{c}\text { Number of } \\
\text { tested females }\end{array}$} & \multicolumn{2}{|c|}{$\begin{array}{l}\text { Number of females with sperm in } \\
\text { seminal receptacle }\end{array}$} & \multicolumn{2}{|c|}{$\begin{array}{c}\text { Number of females with sperm in } \\
\text { uterus/oviduct }\end{array}$} \\
\hline & & & & Sperm & Motile & Sperm & Motile \\
\hline \multirow[t]{3}{*}{ Oregon $\mathrm{R}$} & Oregon $\mathrm{R}$ & 5 & 6 & 5 & 5 & I & No \\
\hline & $X Y$ hs-tra* & 5 & 6 & 4 & 4 & 4 & 1 \\
\hline & $X Y$ hs-tra* & 1 & 6 & 6 & 6 & 4 & 4 \\
\hline \multirow[t]{3}{*}{ dpy-30L26-1 } & Oregon R & 5 & 6 & 0 & - & 0 & - \\
\hline & $X Y$ hs-tra* & 5 & 10 & 0 & - & 3 & No \\
\hline & $X Y$ hs-tra* & 1 & 6 & 0 & - & 6 & No \\
\hline
\end{tabular}

XY hs-tra* - XY fly carrying a single copy of the hs-tra-female plasmid [54]. These flies are females, which contain no eggs, but rather small nonfunctional germ cells in their gonads. As no eggs are laid, sperm can be detected in the uterus or in oviducts long after mating. The experiment shows that mutant sperm is not stored in the seminal receptacle and that it is immotile when remaining in the uterus or in the oviduct. In contrast, motile wildtype sperm is found both in seminal receptacles and in the uterus or oviducts of the analyzed females.

with SET1 protein). SET1C methylates histone $\mathrm{H} 3$ at lysine residue 4 [38]. Yeast strains mutant for SET1, although viable, display defects in cell growth, rDNA silencing [42], and silencing of telomeres and mating type loci [11]. In C. elegans, the dosage compensation complex (DCC), which among other proteins includes Dpy-30, represses X-chromosomal transcription in cells of XX animals. The complex binds preferentially to promoter regions and seems to be required for the early steps of dosage compensation, not for its maintenance [43]. The SET1C complex has also been shown to activate some specific genes, notably for DNA repair genes. This activation is however an indirect one, via repression of a signaling cascade [13]. Direct activation of target genes is also possible, at least in mammals: a human homolog of SET1C, the MLL (mixed-lineage leukemia) complex which also has methyltransferase activity and is ivolved in tumor cell proliferation [44], positively regulates Hox gene expression through binding to promoter sequences [45]. Recent investigations have shown that the human MLL2/ALR complex contains the human ortholog of Dpy-30 [46]. Taken together, these data indicate a conserved role of Dpy-30 family members in the modulation of chromatin structure and transcription.

However, there are clear differences as well. The Drosophila trithorax complex, the homolog of yeast SET1C, is essential for viability. Our findings suggest that flies lacking both Dpy-30L1 and Dpy-30L2 are viable and that Dpy-30 orthologs of Drosophila are not obligatory components of the trithorax complex. The only mutant phenotype we observed was male sterility in the absence of Dpy-30L2. A hallmark of spermatogenesis, the replacement of histones by protamines [47] is not affected in the Dpy-30L2 mutant. Because transcriptional silencing of the spermatid genome seems to occur independently of protamines [39], it appears still possible that Dpy-30L2 is required for proper gene silencing during spermatogenesis.
In yeast, C. elegans and Drosophila, Dpy-30 members serve different but important functions, perhaps converging, in metazoans, on sex-specific gene expression programs, compatible with the fact that the single Dpy-30 ortholog of the mouse is strongly expressed in testes.

\section{Conclusion}

Dumpy-30 (Dpy-30) type proteins are conserved from yeast to humans but their function in higher eukaryotes is only partially understood. Here we have characterized the two Dpy-30 familiy members in Drosophila. Strong expression of Dpy-30L1 can inhibit the activity of MTF-1 (metalresponsive transcription factor 1 ), resulting in elevated sensitivity of flies to cadmium and zinc load. The second member, Dpy-30L2, is only expressed in the male genital tract; targeted gene disruption of $d p y$-30L2 results in male sterility associated with reduced motility of sperm and failure to be transferred to the female's seminal receptacles. Like Drosophila Dpy-30L2, the mouse Dpy-30 homolog is strongly expressed in testes, from where the expressed sequence tag (EST) was obtained [48]. Thus Dpy-30 family members may well be required for male fertility also in mammals.

\section{Methods}

Database searches and computer analysis of the sequences Blast searches for mammalian and yeast orthologs were performed using the NCBI BLAST service. Sequence alignments were performed using ClustalW and Boxshade.

\section{Fly food and heavy metal sensitivity assay}

Flies were raised on standard cornmeal molasses-based food. For sensitivity assays, food was supplemented with $\mathrm{CdCl}_{2}, \mathrm{CuSO}_{4}, \mathrm{ZnCl}_{2}$ or $500 \mu \mathrm{M}$ copper chelator BCS disodium salt hydrate (Sigma-Aldrich 14, 662-5). The concentrations of trace metals in normal food, based on the content of the individual ingredients, are $\sim 5 \mu \mathrm{M}$ for copper and $150 \mu \mathrm{M}$ for zinc. Flies with indicated genotypes 
were allowed to lay eggs for 2 days on normal food or food supplemented with different heavy metals, and eclosed flies were counted. Drosophila cultures were kept at the standard temperature of $25^{\circ} \mathrm{C}$.

\section{Targeted gene disruption by homologous recombination} The targeting construct of the $d p y$-30L1 gene consisted of a DNA segment with $4.5 \mathrm{~kb}$ of upstream and $2.5 \mathrm{~kb}$ of downstream sequences (relative to the transcription unit) that also included another four genes: CG6443, CG17118, CG6750 and Nup170. To disrupt the $d p y-30 L 1$ gene, the coding sequence of YFP with its genuine stop codon followed by the SV40 polyadenylation/transcription termination sequence, was inserted in frame immediately following the ATG start codon. Insertion of YFP resulted in disruption of $d p y-30 L 1$ reading frame as well as a deletion of 17 aa from the coding region; the truncated Dpy$30 \mathrm{~L} 1$ sequence was out of frame relative to the ATG-YFP sequence.

The targeting construct for $d p y$-30L2 gene contained $3.1 \mathrm{~kb}$ of upstream and $3.6 \mathrm{~kb}$ of downstream sequences of the gene. Also in this case, the coding sequence of YFP with its stop codon and the SV40 sequence was inserted after the ATG. Insertion of YFP resulted in the disruption of the $d p y$ $30 \mathrm{~L} 2$ reading frame and in this case deletion of 40 aa from the coding region, generating the following junction: CCTCAGCCCAACAatgC/CCGGACACCAGTTCCATG, where atg stands for the initiator triplet and slash indicates the junction.

Targeting constructs contained an I-SceI cleavage site and were inserted into the pTARG plasmid that contained a multiple cloning site, an I-CreI recognition site, a miniwhite gene, two loxP sites, and two FLP recombinase target sites to release a circular episome for gene targeting [49]. Targeting was performed by a procedure essentially corresponding to that described by $[50,51,36]$. By screening a total of 23000 flies, we recorded five independent events for $d p y$-30L1 (i.e., a frequency of one event in 4600 flies) and two independent events from 6000 screened flies for $d p y-30 L 2$, respectively (a frequency of one event in 3000 flies). The reduction efficiency of the two tandem copies to the mutant was $32 \%$ for $d p y-30 L 1$ and $20 \%$ for dpy30L2. Verification of knockout copies was done using PCR with primers that yielded a different product size in the case of the mutant copy, namely, $1.4 \mathrm{~kb}$ vs. $512 \mathrm{bp}$ (wt) for $d p y-30 L 1$ and $1.1 \mathrm{~kb}$ vs. $200 \mathrm{bp}(\mathrm{wt})$ for dpy-30L2. Sequencing of the fragment confirmed the expected deletion junction: CACATTGCCatgGAGGC/GCTGGCAAGGAGCCAAATG (atg, initiator triplet; slash, junction).

Furthermore, S1 nuclease protection assay revealed a complete absence of genuine mRNA from the two mutated genes.

\section{Genomic rescue}

The rescue construct of $d p y-30 \mathrm{~L} 2$ contained $3.5 \mathrm{~kb}$ of upstream sequence and $4.4 \mathrm{~kb}$ of downstream sequence relative to the transcription unit, whereby the start of $d p y$ $30 \mathrm{~L} 2$ overlaps with the end (400 bp) of the first exon of another gene, namely, CG1136.

The cDNA rescue constructs of mammalian orthologs all contained the $3.5 \mathrm{~kb}$ upstream region, the leader of the $d p y$-30L2 transcript and $4.4 \mathrm{~kb}$ downstream sequence.

\section{Expression pattern determination by fluorescent protein reporter}

Three different transgenic lines that carried knockout constructs (described above) were used to determine the promoter activity of the genes in different tissues of larvae and flies. Pictures were taken with a Zeiss Axiocam.

\section{Preparation of nuclear extracts for EMSA}

Drosophila Schneider S2 cells were transiently transfected with the respective constructs and collected 72 hours later. Electrophoretic mobility shift assays (EMSAs) were performed as described by Radtke et al. [17] and Zhang et al. [18]. Binding reactions were performed by incubating 25 fmoles of $\left[\gamma-{ }^{32} \mathrm{P}\right] \mathrm{ATP}$ end-labeled, 31-bp-long double stranded DNA oligonucleotides containing the core MRE consensus sequence (MRE-s), TGCACAC, with nuclear extracts prepared according to Schreiber et al. [52]. For competition experiments, 5 pmoles of unlabeled oligonucleotides were added to the reaction mixture prior to the addition of the extracts. The MRE-s oligonucleotide used for EMSA is as follows:

\section{5'-CGAGGGAGCTCTGCACACGGCCCGAAAAGTG-3' and}

\section{3'-TCGAGCTCCCTCGAGACGTGTGCCGGGCTTT- TCACAGCT-5.}

\section{Dpy-30L2 and male sterility phenotype}

Constructs H2AvD-GFP, Protamine B-eGFP and Mst77FeGFP-eGFP, used to verify loss of histones with concomitant appearance of protamines and Mst77F during nuclear shaping and chromatin condensation of sperm, are described in Jayaramaiah Raja and Renkawitz-Pohl [40].

\section{Authors' contributions}

$\mathrm{AV}$ did most of the experiments. LA performed control dissections of sperm motility and did essentially all the manuscript handling. DE initiated the study and helped in designing constructs for targeted gene disruption. SJR and RR-P carried out fertilization and followed the fate of sperm in females, MS- $Z$ analyzed the expression of dpy30L2-YFP and sperm motility in females. The project was 
conceived and jointly supervised by WS and OG. All authors read and approved the final manuscript.

\section{Acknowledgements}

We are grateful to Drs. Antonia Manova and Bruno Schmid for technical support, Hasmik Yepiskoposyan, Anand Selvaraj and Dominik Steiger for valuable discussions, to Alisa Davis and George Hausmann for critical reading of the manuscript. This work was supported by the Schweizerischer Nationalfonds, the Kanton of Zürich and by a grant from the project "Controlled Gene Integration" (LSHG-CT-2003-503303) of the European Union to W.S. and by the Deutsche Forschungsgemeinschaft Re628/I2-2, Forschergruppe Chromatin mediated biological decisions to R. R.-P.

\section{References}

I. Andrews GK, Lee DK, Ravindra R, Lichtlen P, Sirito M, Sawadogo M, Schaffner W: The transcription factors MTF-I and USFI cooperate to regulate mouse metallothionein-I expression in response to the essential metal zinc in visceral endoderm cells during early development. Embo / 200I, 20(5): I I I4- I I22.

2. Majumder S, Ghoshal K, Gronostajski RM, Jacob ST: Downregulation of constitutive and heavy metal-induced metallothionein-I expression by nuclear factor I. Gene Expr 200I, 9(4-5):203-2।

3. Wang Y, Lorenzi I, Georgiev O, Schaffner W: Metal-responsive transcription factor-I (MTF-I) selects different types of metal response elements at low vs. high zinc concentration. Biol Chem 2004, 385(7):623-632.

4. Ogra Y, Suzuki K, Gong P, Otsuka F, Koizumi S: Negative regulatory role of $\mathrm{SpI}$ in metal responsive element-mediated transcriptional activation. J Biol Chem 200I, 276( 19): I6534-I6539.

5. Cramer M, Nagy I, Murphy BJ, Gassmann M, Hottiger MO, Georgiev $O$, Schaffner W: NF-kappaB contributes to transcription of placenta growth factor and interacts with metal responsive transcription factor-I in hypoxic human cells. Biol Chem 2005, 386(9):865-72.

6. Giot L, Bader JS, Brouwer C, Chaudhuri A, Kuang B, Li Y, Hao YL, Ooi CE, Godwin B, Vitols E, et al.: A protein interaction map of Drosophila melanogaster. Science 2003, 302(565I): I727-1736.

7. FlyBase: A Database of Drosophila Genes \& Genomes [http:l /www.flybase.org]

8. Hsu DR, Meyer B]: The dpy-30 gene encodes an essential component of the Caenorhabditis elegans dosage compensation machinery. Genetics 1994, 137(4):999-1018.

9. Hsu DR, Chuang PT, Meyer B]: DPY-30, a nuclear protein essential early in embryogenesis for Caenorhabditis elegans dosage compensation. Development I995, I 2 I ( I 0):3323-3334.

10. Roguev A, Schaft D, Shevchenko A, Pijnappel WW, Wilm M, Aasland R, Stewart AF: The Saccharomyces cerevisiae SETI complex includes an Ash2 homologue and methylates histone 3 lysine 4. Embo J 200I, 20(24):7I37-7I48.

II. Nislow C, Ray E, Pillus L: SET I, a yeast member of the trithorax family, functions in transcriptional silencing and diverse cellular processes. Mol Biol Cell 1997, 8(I 2):242I-2436.

12. Corda Y, Schramke V, Longhese MP, Smokvina T, Paciotti V, Brevet V, Gilson E, Geli V: Interaction between SET I p and checkpoint protein Mec3p in DNA repair and telomere functions. Nat Genet 1999, 2 I (2):204-208.

13. Schramke V, Neecke H, Brevet V, Corda Y, Lucchini G, Longhese MP, Gilson E, Geli V: The SETIDelta mutation unveils a novel signaling pathway relayed by the Rad53-dependent hyperphosphorylation of replication protein $A$ that leads to transcriptional activation of repair genes. Genes Dev 200I, I 5(14): 1845-1858.

14. Newlon MG, Roy M, Morikis D, Hausken ZE, Coghlan V, Scott JD, Jennings PA: The molecular basis for protein kinase $A$ anchoring revealed by solution NMR. Nat Struct Biol 1999, 6(3):222-227.

15. Andrews J, Bouffard GG, Cheadle C, Lu J, Becker KG, Oliver B: Gene discovery using computational and microarray analysis of transcription in the Drosophila melanogaster testis. Genome Res 2000, I ( ( I 2):2030-2043.
16. Westin G, Schaffner W: A zinc-responsive factor interacts with a metal-regulated enhancer element (MRE) of the mouse metallothionein-I gene. Embo J I 988, 7(12):3763-3770.

I7. Radtke F, Heuchel R, Georgiev O, Hergersberg M, Gariglio M, Dembic Z, Schaffner W: Cloned transcription factor MTF-I activates the mouse metallothionein I promoter. Embo / 1993, I 2(4): | 355-1362

18. Zhang B, Egli D, Georgiev O, Schaffner W: The Drosophila homolog of mammalian zinc finger factor MTF-I activates transcription in response to heavy metals. Mol Cell Biol 200I, 2I(I4):4505-45I4.

19. Balamurugan K, Egli D, Selvaraj A, Zhang B, Georgiev O, Schaffner W: Metal-responsive transcription factor (MTF-I) and heavy metal stress response in Drosophila and mammalian cells: a functional comparison. Biol Chem 2004, 385(7):597-603.

20. Gunes C, Heuchel R, Georgiev O, Muller KH, Lichtlen P, Bluthmann $H$, Marino S, Aguzzi A, Schaffner W: Embryonic lethality and liver degeneration in mice lacking the metal-responsive transcriptional activator MTF-I. Embo J 1998, I 7(10):2846-2854.

21. Andrews GK: Cellular zinc sensors: MTF-I regulation of gene expression. Biometals 200I, 14(3-4):223-37.

22. Wang $Y$, Wimmer $U$, Lichtlen $P$, Inderbitzin D, Stieger B, Meier PJ, Hunziker L, Stallmach T, Forrer R, Rulicke T, Georgiev O, Schaffner W: Metal-responsive transcription factor-I (MTF-I) is essential for embryonic liver development and heavy metal detoxification in the adult liver. FASEB / 2004, I 8( I0): I07|-9.

23. Lichtlen $P$, Schaffner : Putting its fingers on stressful situations: the heavy metal-regulatory transcription factor MTF-I. Bioessays 200I, 23(I I): 1010-1017.

24. Giedroc DP, Chen X, Apuy JL: Metal response element (MRE)binding transcription factor-I (MTF-I): structure, function, and regulation. Antioxid Redox Signal 200I, 3(4):577-96. Review

25. Andrews GK: Regulation of metallothionein gene expression by oxidative stress and metal ions. Biochem Pharmacol 2000, 59(I):95-104.

26. Kagi JH: Overview of metallothionein. Methods Enzymol 1991, 205:613-626

27. Palmiter RD: The elusive function of metallothioneins. Proc Natl Acad Sci USA 1998, 95( ( 5):8428-8430.

28. Egli D, Selvaraj A, Yepiskoposyan H, Zhang B, Hafen E, Georgiev O Schaffner W: Knockout of 'metal-responsive transcription factor' MTF-I in Drosophila by homologous recombination reveals its central role in heavy metal homeostasis. Embo J 2003, 22(I): $100-108$

29. Selvaraj A, Balamurugan K, Yepiskoposyan $H$, Zhou H, Egli D, Georgiev $O$, Thiele DJ, Schaffner W: Metal-responsive transcription factor (MTF-I) handles both extremes, copper load and copper starvation, by activating different genes. Genes Dev 2005 , 19(8):89|-896

30. Wimmer U, Wang $Y$, Georgiev O, Schaffner W: Two major branches of anti-cadmium defense in the mouse: MTF-I/ metallothioneins and glutathione. Nucleic Acids Res 2005, 33( 18):57|5-5727.

31. Yepiskoposyan H, Egli D, Fergestad T, Selvaraj A, Treiber C, Multhaup G, Georgiev O, Schaffner W: Transcriptome response to heavy metal stress in Drosophila reveals a new zinc transporter that confers resistance to zinc. Nucleic Acids Res 2006, 34( I 7):4866-4877.

32. Schneider I: Cell lines derived from late embryonic stages of Drosophila melanogaster. J Embryol Exp Morphol 1972, 27(2):353-365.

33. FlyTED: the Drosophila Testis Gene Expression Database [http://www.fly-ted.org]

34. FlyAtlas: the Drosophila adult gene expression atlas [http:// www.flyatlas.org]

35. Chintapalli VR, Wang J, Dow JAT: Using FlyAtlas to identify better Drosophila models of human disease. Nature Genetics 39:7I5-720.

36. Rong YS, Titen SW, Xie HB, Golic MM, Bastiani M, Bandyopadhyay P, Olivera BM, Brodsky M, Rubin GM, Golic KG: Targeted mutagenesis by homologous recombination in $D$. melanogaster. Genes Dev 2002, I6( I 2): | $568-158 \mid$.

37. Miller T, Krogan NJ, Dover J, Erdjument-Bromage H, Tempst P, Johnston M, Greenblatt JF, Shilatifard A: COMPASS: a complex of proteins associated with a trithorax-related SET domain protein. Proc Natl Acad Sci USA 200I, 98(23): I2902-I 2907. 
38. Nagy PL, Griesenbeck J, Kornberg RD, Cleary ML: A trithoraxgroup complex purified from Saccharomyces cerevisiae is required for methylation of histone H3. Proc Natl Acad Sci USA 2002, 99(I):90-94.

39. Russell SR, Kaiser K: Drosophila melanogaster male germ linespecific transcripts with autosomal and Y-linked genes. Genetics 1993, I34(I):293-308.

40. Jayaramaiah Raja S, Renkawitz-Pohl R: Replacement by Drosophila melanogaster protamines and Mst77F of histones during chromatin condensation in late spermatids and role of sesame in the removal of these proteins from the male pronucleus. Mol Cell Biol 2005, 25(14):6I65-6I77.

4I. Rong YS: Gene targeting by homologous recombination: a powerful addition to the genetic arsenal for Drosophila geneticists. Biochem Biophys Res Commun 2002, 297(I): I-5.

42. Briggs SD, Bryk M, Strahl BD, Cheung WL, Davie JK, Dent SY, Winston $\mathrm{F}$, Allis CD: Histone $\mathrm{H} \mathbf{3}$ lysine $\mathbf{4}$ methylation is mediated by SETI and required for cell growth and $r D N A$ silencing in Saccharomyces cerevisiae. Genes Dev 200I, I 5(24):3286-3295.

43. Ercan S, Giresi PG, Whittle CM, Zhang X, Green RD, Lieb JD: $\mathbf{X}$ chromosome repression by localization of the $C$. elegans dosage compensation machinery to sites of transcription initiation. Nat Genet 2007, 39(3):403-408.

44. Lüscher-Firzlaff J, Gawlista I, Vervoorts J, Kapelle K, Braunschweig T, Walsemann G, Rodgarkia-Schamberger C, Schuchlautz H, Dreschers S, Kremmer E, Lilischkis R, Cerni C, Wellmann A, Lüscher B: The human trithorax protein hASH2 functions as an oncoprotein. Cancer Res 68(3):749-58. 2008 Feb I;

45. Milne TA, Briggs SD, Brock HW, Martin ME, Gibbs D, Allis CD, Hess JL: MLL targets SET domain methyltransferase activity to Hox gene promoters. Molecular cell 2002, I0(5): I I07- I I I7.

46. Issaeva I, Zonis Y, Rozovskaia T, Orlovsky K, Croce CM, Nakamura T, Mazo A, Eisenbach L, Canaani E: Knockdown of ALR (MLL2) reveals ALR target genes and leads to alterations in cell adhesion and growth. Mol Cell Biol 2007, 27(5):1889-1903.

47. Fuller MT: Genetic control of cell proliferation and differentiation in Drosophila spermatogenesis. Seminars in cell \& developmental biology 1998, 9(4):433-444.

48. Okazaki $Y$, Furuno M, Kasukawa T, Adachi J, Bono H, Kondo S, Nikaido I, Osato N, Saito R, Suzuki H, et al.: Analysis of the mouse transcriptome based on functional annotation of 60,770 fulllength cDNAs. Nature 2002, 420(69 I 5):563-573.

49. Egli D, Yepiskoposyan H, Selvaraj A, Balamurugan K, Rajaram R, Simons A, Multhaup G, Mettler S, Vardanyan A, Georgiev O, Schaffner W: A family knockout of all four Drosophila metallothioneins reveals a central role in copper homeostasis and detoxification. Mol Cell Biol 2006, 26(6):2286-2296.

50. Rong YS, Golic KG: Gene targeting by homologous recombination in Drosophila. Science 2000, 288(5473):2013-2018.

51. Rong YS, Golic KG: A targeted gene knockout in Drosophila. Genetics 200I, I57(3): |307-|3|2.

52. Schreiber E, Matthias P, Müller MM, Schaffner W: Rapid detection of octamer binding proteins with 'mini-extracts', prepared from a small number of cells. Nucleic Acids Res 17(15):6419. 1989 August II;

53. Wood KV, Lam YA, McElroy WD: Introduction to beetle luciferases and their applications. J Biolumin Chemilumin 1989, 4(I):289-30I.

54. McKeown M, Belote JM, Boggs RT: Ectopic expression of the female transformer gene product leads to female differentiation of chromosomally male Drosophila. Cell 1988 53(6):887-895.

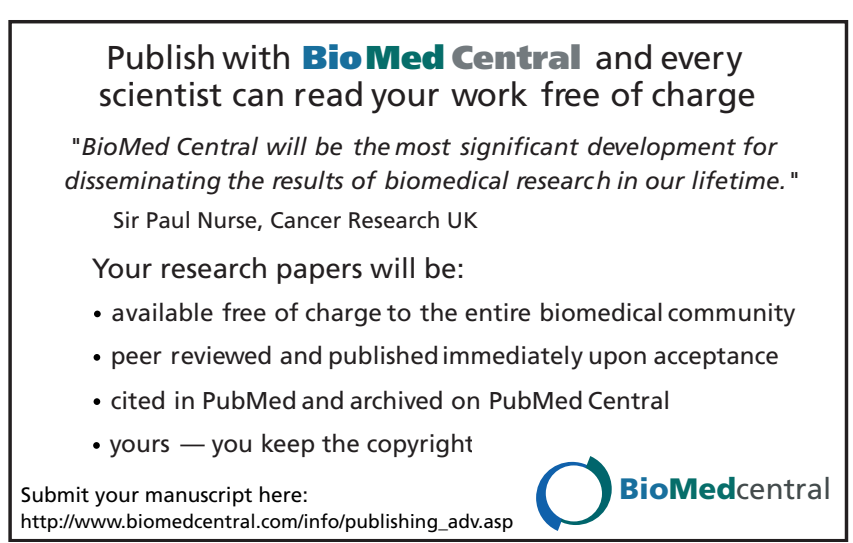

